\title{
Efficacy of microsurgery in Reinke's oedema evaluated by traditional voice assessment integrated with the Vocal Extent Measure (VEM)
}

\author{
Efficacia della microchirurgia nell'edema di Reinke analizzata con \\ la valutazione vocale tradizionale integrata con la Vocal Extent Measure (VEM)
}

\author{
T. SALMEN ${ }^{1}$, T. ERMAKOVA² ${ }^{2}$, A. SCHINDLER ${ }^{3}$, S.-R. KO ${ }^{1}$, Ö. GÖKTAS ${ }^{1}$, M. GROSS ${ }^{1}$, T. NAWKA ${ }^{1}$, P.P. CAFFIER 1 \\ ${ }^{1}$ Department of Audiology and Phoniatrics of Charité, University Medicine Berlin, Berlin, Germany; ${ }^{2}$ Department of \\ Business Informatics, Social Media and Data Science, University of Potsdam, Potsdam, Germany; ${ }^{3}$ Phoniatric Unit, \\ Department of Biomedical and Clinical Sciences "L. Sacco", Università degli Studi di Milano, Milan, Italy
}

\section{SUMMARY}

There are few data analysing to what specific extent phonomicrosurgery improves vocal function in patients suffering from Reinke's oedema (RE). The recently introduced parameter vocal extent measure (VEM) seems to be suitable to objectively quantify vocal performance. The purpose of this clinical prospective study was to investigate the outcomes of phonomicrosurgery in $60 \mathrm{RE}$ patients $(6$ male, 54 female; $56 \pm 8$ years $([$ mean $\pm \mathrm{SD}])$ by analysing its effect on subjective and objective vocal parameters with particular regard to VEM. Treatment efficacy was evaluated at three months after surgery by comparing pre- and postoperative videolaryngostroboscopy (VLS), auditory-perceptual assessment (RBH-status), voice range profile (VRP), acoustic-aerodynamic analysis and patient's self-assessment using the voice handicap index (VHI-9i). Phonomicrosurgically, all RE were carefully ablated. VLS revealed removal or substantial reduction of oedema with restored periodic vocal fold vibration. All subjective and most objective acoustic and aerodynamic parameters significantly improved. The VEM increased on average from $64 \pm 37$ to $88 \pm 25(\mathrm{p}<0.001)$ and the dysphonia severity index (DSI) from $0.5 \pm 3.4$ to $2.9 \pm 1.9$. Both parameters correlated significantly with each other $(\mathrm{rs}=0.70)$. RBH-status revealed less roughness, breathiness and overall grade of hoarseness $(2.0 \pm 0.7 \mathrm{vs} 1.3 \pm 0.7)$. The VHI- $9 \mathrm{i}$-score decreased from $18 \pm 8$ to $12 \pm 9$ points. The average total vocal range enlarged by $4 \pm 7$ semitones, and the mean speaking pitch rose by $2 \pm 4$ semitones. These results confirm that: (1) the use of VEM in RE patients objectifies and quantifies their vocal capacity as documented in the VRP, and (2) phonomicrosurgery is an effective, objectively and subjectively satisfactory therapy to improve voice in RE patients.

KEY WORDS: Vocal Extent Measure (VEM) • Phonomicrosurgery $\bullet$ Reinke's oedema $\bullet$ Voice function diagnostics $\bullet$ Voice range profile quantification

\section{RIASSUNTO}

Esistono pochi dati che mostrino di quanto specificatamente la microfonochirurgia migliori la funzione vocale in pazienti affetti da edema di Reinke (RE). Il parametro Misura di Estensione Vocale (VEM) recentemente introdotto sembra in grado di quantificare oggettivamente la performance vocale. Lo scopo di questo studio clinico prospettico era di investigare l'outcome della microfonochirurgia in 60 pazienti con RE (6 maschi, 54 femmine; $56 \pm 8$ anni [media $\pm S D$ ]) analizzando il suo effetto su parametri vocali soggettivi e oggettivi con particolare riferimento al VEM. L'efficacia di trattamento è stata valutata tre mesi dopo la chirurgia confrontando la videolaringostroscopia (VLS), la valutazione percettiva-uditiva (stato RBH), il voice range profile (VRP), l'analisi acustica-aerodinamica e l'autovalutazione del paziente usando il voice handicap index (VHI9i). Tutti gli RE sono stati attentamente rimossi con microfonochirurgia. La VLS ha mostrato la rimozione o la sostanziale riduzione dell'edema con ripristino della periodica vibrazione cordale. Tutti i parametri soggettivi e la maggior parte dei parametri oggettivi sono migliorati in maniera significativa. La VEM è aumentata in media da $64 \pm 37$ a $88 \pm 25$ ( $p<0,001)$, il dysphonia severity index (DSI) da 0,5 $\pm 3,4$ a 2,9 $\pm 1,9$. Entrambe $i$ parametri correlavano significativamente fra di loro $(r s=0,70)$. Lo stato $R B H$ ha mostrato minore raucedine, voce soffiata e grado generale di disfonia $(2,0 \pm 0,7$ vs 1,3 \pm 0,7). Il punteggio del VHI-9i è diminuito da $18 \pm 8$ a $12 \pm 9$ punti. Il range vocale totale medio si è allargato di $4 \pm 7$ semitoni, la frequenza media del parlato è aumentata di $2 \pm 4$ semitoni. Questi risultati confermano che (1) l'utilizzo della VEM nei pazienti con $R E$ rende oggettiva e quantifica la loro capacità vocale, come documentata dal VRP, e che (2) la microfonochirurgia è una terapia efficace e soddisfacente dal punto di vista soggettivo e oggettivo per migliorare la voce nei pazienti con RE.

PAROLE CHIAVE: Misura di Estensione Vocale (VEM) • Microfonochirurgia $\bullet$ Edema di Reinke Diagnosi della funzione vocale • Quantificazione del voice range profile 


\section{Introduction}

Reinke's oedema (RE) is a disease of the superficial lamina propria (SLP), also known as Reinke's space ${ }^{12}$ and describes a pronounced chronic swelling of the SLP ${ }^{34}$. Reinke's space is very important for voice production and quality as it is responsible for vocal fold (VF) vibration. Impaired structural integrity reduces VF function and results in symptoms such as dysphonia ${ }^{1}$. The disease can be uni- or bi-lateral ${ }^{5-8}$, and is one of the most common benign lesions of the larynx, showing very low tendency to malignancy 156 8-10. Histopathologically, RE reveals epithelial basement membrane thickening in combination with oedematous lakes and increased submucosal vessel wall thickness, while the epithelium itself is smooth ${ }^{511}$. Fluid accumulates under the epithelium, an oedematous transudate which turns gelatinous later ${ }^{812}$. The bleachwhite swelling is sessile and floating during phonation ${ }^{56}$. The initiating trauma remains unknown ${ }^{358}$, although there is a strong association with smoking ${ }^{137-10} 13-15$. Further potential factors are vocal overuse and reflux 3781015 . Mostly there are several risk factors existent at the same time, which have a close interrelation ${ }^{16}$.

$\mathrm{RE}$ is especially common among women $>40$ years of age 4101718 . The voice sounds deep and hoarse 48101719 . Since there exists no efficient drug therapy, conventional microlaryngoscopic surgery with subsequent vocal rehabilitation is considered the best RE treatment ${ }^{8}$. Cessation of smoking alone is insufficient ${ }^{20}$, and for long-term therapy success it is important to have voice therapy and abstinence from smoking post-operatively 38171920 . Most patients with RE consult a physician at an advanced stage, so that the illness usually lasts months or years ${ }^{5}$. Surgery is indicated in case of symptomatic dysphonia, airway obstruction and non-response to anti-reflux management, voice therapy and smoking cessation. Continued smoking is a relative contraindication for surgical intervention, as it induces RE recurrence ${ }^{12}$.

There are scarse data investigating to what extent phonomicrosurgery in RE affects vocal function, and hence the specific benefits that patients can expect from the operation. Thus, this study examined phonomicrosurgical outcomes in RE by evaluating its impact on subjective and objective voice parameters. Particular attention was given to the vocal extent measure (VEM), a recently introduced and easy-to-use parameter, which seems to be suitable to objectively quantify vocal performance ${ }^{21}$. The intention was to investigate VEM changes with phonomicrosurgical treatment in RE patients and to compare its performance to that of established vocal parameters including the dysphonia severity index (DSI).

\section{Materials and methods}

\section{Study design and participants}

In a clinical prospective study, RE patients were treated phonomicrosurgically via direct microlaryngoscopy in intubation narcosis. Clinical examination and data collection was done at the initial pretherapeutic visit, during the operation and at regular follow-ups at 2 weeks and 3 months after surgery. Assessment of operation outcomes took place at the 3-month interval by comparing the preand post-operative data. In patients who missed this appointment, follow-up examination was set at a later date. A total of 60 patients consecutively presenting at the Department of Audiology and Phoniatrics of Charité, University Medicine Berlin, Germany were included in the study. Selection criteria comprised: clear VLS-based finding, suffering from dysphonia or dyspnoea, absence of spontaneous RE resolution, lack of improvement under conservative therapy, complete treatment documentation and informed consent. The trial was conducted in accordance with the Declaration of Helsinki and approved by the local ethics review board.

\section{Surgical procedure and post-operative care}

RE were ablated phonomicrosurgically using the microflap technique. Surgery was performed bilaterally during the same session, preserving the anterior commissure to avoid web formation ${ }^{812}$. After inspection and palpation under the operation microscope, the superior/lateral VF aspect was incised with a sickle knife. The microflap between the epithelium and the polypoid material was raised using a $30^{\circ}$ flap elevator. The exposed oedematous and gelatinous material was removed, mainly by suction. We left some material in the SLP behind to regenerate Reinke's space and preserve vibratory characteristics ${ }^{312}$. Finally, redundant epithelium was trimmed so that the edges of the flap kept closely with minimal mucosal dehiscence ${ }^{12}$. Post-operatively, patients were ordered voice rest for three days, followed by logopaedic vocal reestablishment. In addition, all patients received vocal hygiene counselling and were instructed to reappear in case of recurring voice impairment.

\section{Examination instruments and criteria}

A high-resolution rigid videolaryngoscope $\left(10 \mathrm{~mm} ; 70^{\circ}\right)$ with integrated microphone was used to perform digital VLS (XION medical, Berlin, Germany) ${ }^{22}$. Laryngoscopy allowed RE classification according to Yonekawa ${ }^{23}$. RE type $\mathrm{I}$ is described as an oedematous swelling of the upper VF surface when the glottis is widely open. In RE type II, 
the oedema extends from the upper to the lower surface and the VF touch only in the front section. RE type III is so extensive that there is only a small remaining space in the posterior part of the glottis. Patients with more localised findings too small to fit to type I were classified as marginal oedema. Furthermore, it was recorded whether the swelling was uni- or bi-lateral.

Standardised voice range profile (VRP) registrations and acoustic-aerodynamic analyses were performed with the DiVAS software (XION medical, Berlin, Germany) to obtain objective quantitative measurements of speaking and singing voice ${ }^{2124}$. The following frequency, intensity and derived parameters were measured: lowest vocalisation (I_min), highest tone (F0_max), lowest tone (F0_min), mean speaking pitch (MSP_dB(A), MSP_Hz), maximum phonation time (MPT), jitter and DSI ${ }^{25}$. For better comparison of (logarithmical) frequency data in both genders (F0_max, F0_min, MSP_Hz), the corresponding amount of semitones related to the human hearing threshold of $16 \mathrm{~Hz}$ was used for further evaluation (ST_max, ST_min, ST_MSP). Derived from that, the total vocal range (VR) was assessed ([ST_max] - [ST_min]). Additionally, the VEM, a recently introduced measure for quantification of the patient's dynamic performance and frequency range, was calculated as a relation of area and perimeter of the VRP. The underlying idea is that VRP shape should not show abrupt differences in the dynamic range of notes along the frequency range. Well balanced dynamic extent approximates the VRP shape to a circle where the area is biggest for a given perimeter compared to other geometric figures. Each deviance from the idealised circular shape, where the dynamic range is evenly distributed over the tonal extent, indicates a decrease in vocal performance. Thus, the VEM multiplies the VRP area by the quotient of the VRP perimeter and the theoretical perimeter of a circle with the same area as the profile itself. The detailed mathematical derivation is explained elsewhere ${ }^{21}$. As a result, the VEM is scaled one-dimensionally to a range of 0 to 150 , whereas these limits may be exceeded on both sides. A small vocal capacity is characterised by a small VEM; conversely, a large VRP results in a high VEM.

The RBH-system was used for auditory-perceptual voice evaluation when patients were reading the standardised text "The north wind and the sun" ${ }^{26}$. The perceived roughness $(\mathrm{R})$, breathiness $(\mathrm{B})$ and overall hoarseness $(\mathrm{H})$ of the patient's voice was scored on a scale from 0 to $3(0$ : normal, 1: mild, 2: moderate, 3: severe). To achieve objectivity, all 120 audio recordings were shuffled and blinded for patient allocation and pre-/post-operative status. Six raters (3 phoniatric physicians, 2 medical students, 1 medical technical assistant) independently rated all audio files. Further analysis was done using the mean group rating of each audio recording.

The Voice Handicap Index VHI-9i was applied for patient's self-assessment of voice ${ }^{27}$. They rated nine questions on a scale from 0 to 4 ( 0 : never, 1: almost never, 2: sometimes, 3: almost always, 4: always), and one question regarding the self-perceived voice impairment at the present time (VHIs) on a scale from 0 to 3 (0: normal, 1: mild, 2: moderate, 3: severe). The questionnaires were filled out pre- and post-therapeutically to record subjective perception of vocal changes and to quantify the impact of the voice disorder on the patient's quality of life.

\section{Outcome measures}

The primary outcome measure was change of VEM at three months post-operatively. Secondary outcomes included surgery-induced differences of VLS as well as established objective and subjective vocal parameters assessing the scale of benefits which can be expected from the operation.

\section{Statistical analysis}

Descriptive statistics were calculated for all vocal function parameters before and after surgery, as well as their changes. Spearman's rank-order correlation (rs) was applied to examine the strength and direction of association between the pre- and post-operatively measured characteristics and their differences. The reliability of agreement among all six raters when assigning categorical $\mathrm{RBH}$ ratings to the blinded patient's voices was checked using Fleiss'kappa. The Mann-Whitney-Wilcoxon test served to analyse whether vocal function parameters significantly improved due to the treatment. Mean values and $95 \%$ confidence intervals for these changes were calculated. Significance was set at $\mathrm{p}<0.05$. All statistical tests and graphics were done with $\mathrm{R}$ version 3.2.2 (GNU project, Free Software Foundation, Boston, MA).

\section{Results}

\section{Sample description and pre-operative assessment}

The study cohort $(n=60)$ included 54 females and 6 males with an age ranged between 30 and 74 years $(56 \pm 8$ years [mean \pm SD]). Regarding medical history, 53 patients gave information about smoking, with only one RE patient being non-smoker. While $57 \%$ of participants (34/60) had no reflux, 8 patients indicated frequent symptoms and 18 patients suffered from reflux disease. Thirty-three individuals used their voice in a non-professional manner (e.g., business (wo)men, clerks, labourers), whereas 20 patients had 
a high vocal strain in their profession (e.g., teachers, lecturers), 4 of them as elite vocal performers (singers). Subjects of both sexes were comparable in terms of age and sociodemographic characteristics (see Table I for details).

Laryngoscopy showed that 40 participants had bilateral and 20 patients unilateral RE ( $\mathrm{n}=10$ at each side). Nineteen RE were classified as Yonekawa type I (32\%), 29 as type II (48\%) and 8 as type III (13\%). Notably, none of the professional voice users had a RE type III. Four patients were grouped as marginal oedema (7\%). Pre-operative analysis revealed significant differences between subgroups $(\mathrm{p}<0.05)$, showing increasingly poor voice parameters with higher grades of oedema. Exemplarily, Figure 1 (left side) presents the pre-therapeutic findings for VEM, DSI and MSP_Hz in all subgroups.

Subjective auditory perception of voices in the total RE group was assessed with a mean of R2 B1 H2 (range 0-3). The VHI-9i had an average score of $18 \pm 8$, corresponding to moderate self-assessed complaints. Moderate impairment was further affirmed by the obtained acoustic-aerodynamic parameters (e.g., VEM $64 \pm 37$; DSI $0.5 \pm 3.4$; MPT $9 \pm 5 \mathrm{sec}$.). The correlation analysis revealed that both DSI and VEM correlated with age ( $\mathrm{rs}=-0.39$ and $\mathrm{rs}=-0.36), \mathrm{R}(\mathrm{rs}=-0.50$ and $\mathrm{rs}=-0.35), \mathrm{H}(\mathrm{rs}=-0.49$ and $\mathrm{rs}=-0.40)$, VR ( $\mathrm{rs}=0.44$ and $\mathrm{rs}=0.74)$ and with each other ( $\mathrm{rs}=0.47)$. $\mathrm{R}$ and $\mathrm{H}$ correlated nearly perfectly ( $\mathrm{rs}=0.97$ ), both criteria further correlated with $\mathrm{B}$ ( $\mathrm{rs}=0.36$ and $\mathrm{rs}=0.40)$, VHI $(\mathrm{rs}=0.29$ and $\mathrm{rs}=0.28)$, and MSL_Hz (rs $=-0.42$ and $\mathrm{rs}=-0.38)$.

\section{Post-operative assessment}

All RE were completely ablated (39/60 patients) or significantly reduced (21/60). VLS showed no VF scarring. Within the mean post-operative observation period of $231 \pm 287$ days, no side effects or recurrences became apparent. Regarding functional aspects, patency of the glottis was regained and mucosal wave propagation was restored. The VF edge was fully straight in 39 cases with complete ablation (65\%). All 21 cases with residual oedema (35\%) showed substantial improvement with Yonekawa type I in 18 patients (30\%) and type II in three patients $(5 \%)$. Figure 2 gives a typical impression of preand post-operative objective findings in a RE patient initially classified as Yonekawa type III.

Regarding vocal function, all acoustic and aerodynamic parameters apart from MSP_dB(A) $(\mathrm{p}=0.29)$ signifi-

Table I. Patient characteristics. Unless otherwise specified, data are expressed as number of patients and percentage of group.

\begin{tabular}{|c|c|c|c|c|c|c|}
\hline Characteristics & $\begin{array}{c}\text { No. } \\
\text { of all patients }\end{array}$ & $\begin{array}{l}\% \text { of total group } \\
\qquad(n=60)\end{array}$ & $\begin{array}{c}\text { No. } \\
\text { of male patients }\end{array}$ & $\begin{array}{l}\% \text { of male group } \\
\qquad(n=6)\end{array}$ & $\begin{array}{c}\text { No. } \\
\text { of female patients }\end{array}$ & $\begin{array}{l}\% \text { of female group } \\
\quad(n=54)\end{array}$ \\
\hline \multicolumn{7}{|l|}{ Gender } \\
\hline Male & 6 & $10 \%$ & - & - & - & - \\
\hline Female & 54 & $90 \%$ & - & - & - & - \\
\hline \multicolumn{7}{|l|}{ Age } \\
\hline Years (mean \pm SD) & $56 \pm 8$ & - & $57 \pm 11$ & - & $56 \pm 8$ & - \\
\hline \multicolumn{7}{|l|}{ Main voice use } \\
\hline Non-professional & 33 & $55 \%$ & 4 & $67 \%$ & 29 & $54 \%$ \\
\hline Professional & 20 & $33 \%$ & 2 & $33 \%$ & 18 & $33 \%$ \\
\hline Not stated & 7 & $12 \%$ & NA & NA & 7 & $13 \%$ \\
\hline \multicolumn{7}{|l|}{ Reflux symptoms } \\
\hline Reflux & 26 & $43 \%$ & 3 & $50 \%$ & 23 & $43 \%$ \\
\hline No reflux & 34 & $57 \%$ & 3 & $50 \%$ & 31 & $57 \%$ \\
\hline \multicolumn{7}{|c|}{ Edema classification } \\
\hline Marginal oedema & 4 & $7 \%$ & NA & NA & 4 & $7 \%$ \\
\hline Yonekawa type I & 19 & $32 \%$ & 3 & $50 \%$ & 16 & $30 \%$ \\
\hline Yonekawa type II & 29 & $48 \%$ & 2 & $33 \%$ & 27 & $50 \%$ \\
\hline Yonekawa type III & 8 & $13 \%$ & 1 & $17 \%$ & 7 & $13 \%$ \\
\hline \multicolumn{7}{|l|}{ Oedema occurrence } \\
\hline Left vocal fold & 10 & $17 \%$ & NA & NA & 10 & $18 \%$ \\
\hline Right vocal fold & 10 & $17 \%$ & 2 & $33 \%$ & 8 & $15 \%$ \\
\hline Both vocal folds & 40 & $66 \%$ & 4 & $67 \%$ & 36 & $67 \%$ \\
\hline \multicolumn{7}{|l|}{ Tobacco smoking } \\
\hline Smoking & 52 & $86 \%$ & 6 & $100 \%$ & 46 & $85 \%$ \\
\hline Non-smoking & 1 & $2 \%$ & NA & NA & 1 & $2 \%$ \\
\hline Not stated & 7 & $12 \%$ & NA & NA & 7 & $13 \%$ \\
\hline
\end{tabular}

NA: not applicable; No: number. 


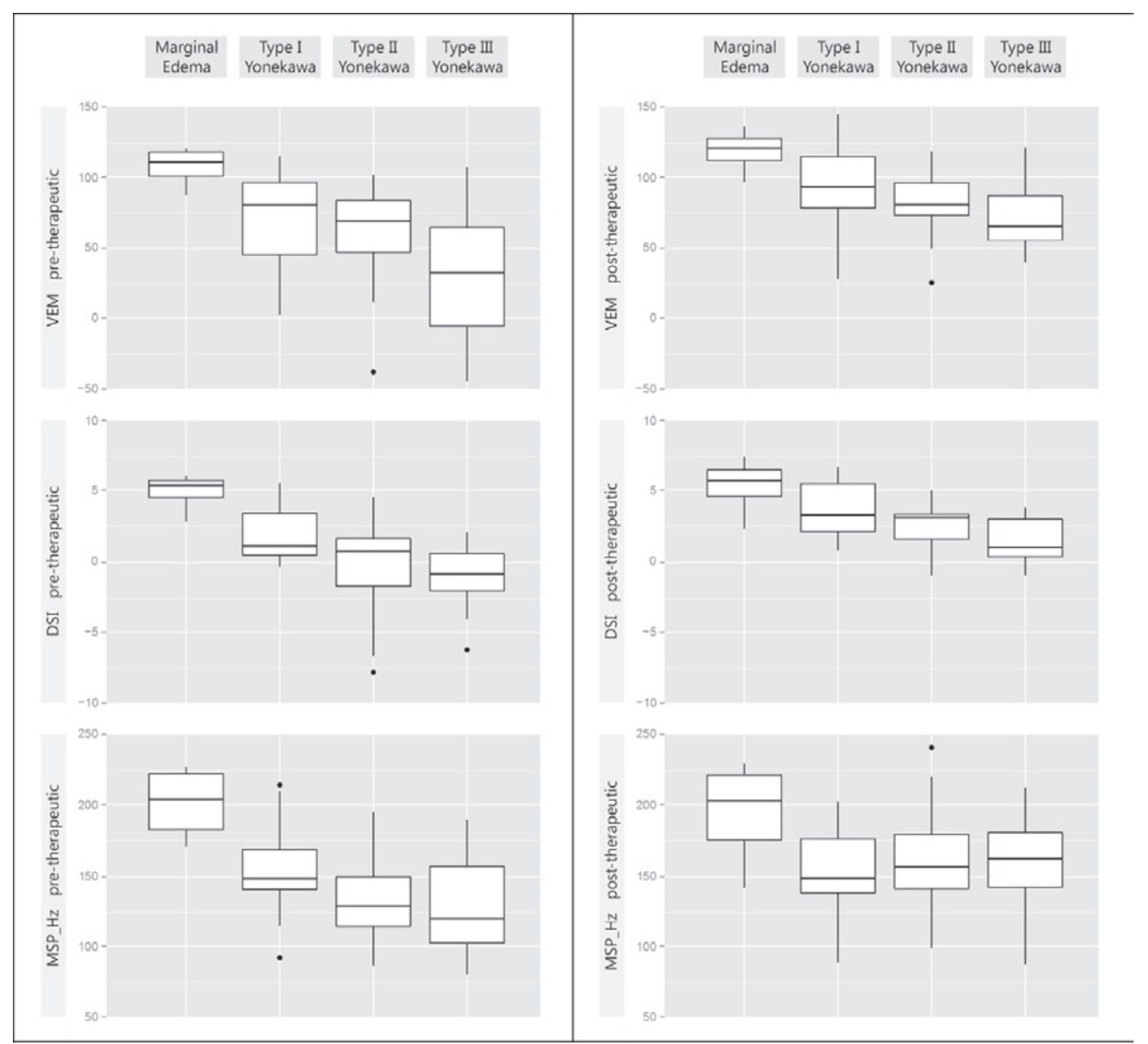

Fig. 1. Pre-therapeutic initial data (left) and post-therapeutic results (right) in all patient subgroups for selected vocal parameters (VEM, DSI, and MSP_Hz). The boxplots display the median, quartiles, range of values covered by the data and any outliers (single spots).

cantly improved at the $0.1 \%$ level (i.e. $\mathrm{p}<0.001$; pre vs post). The mean VEM increased by $25 \pm 30(64 \pm 37 \mathrm{vs}$ $88 \pm 25)$, the DSI by $2.4 \pm 3.1(0.5 \pm 3.4$ to $2.9 \pm 1.9)$. Both parameters correlated significantly with each other also post-operatively $(\mathrm{rs}=0.70)$. Mean MPT increased by $2 \pm 5$ seconds $(9 \pm 5$ vs $11 \pm 4)$, MSP_Hz rose by $2 \pm 4$ semitones $(142.6 \pm 34.6 \mathrm{~Hz}$ vs $159.5 \pm 33.0 \mathrm{~Hz})$, and VR enlarged by $4 \pm 7$ semitones ( $17 \pm 7$ vs $21 \pm 6$ ). Selected objective parameters before and after RE removal are graphically displayed in Figure 3. Post-therapeutic findings for VEM, DSI and MSP_Hz were also itemised according to oedema subtypes (Fig. 1, right side). Inspection indicates convergence of therapeutic results, whereas pre-operative status affects the post-operative outcome. Analysis revealed significant differences between groups $(\mathrm{p}<0.05)$, with greatest mean improvement in Yonekawa type III patients. To evaluate the magnitude of improvement and thus the extent of the operation-related benefit, Table II presents the mean differences between pre- and post-therapeutic values of both objective acoustic/aerodynamic parameters and subjective VHI-9i/VHIs vocal parameters and the $95 \%$ confidence intervals. These 


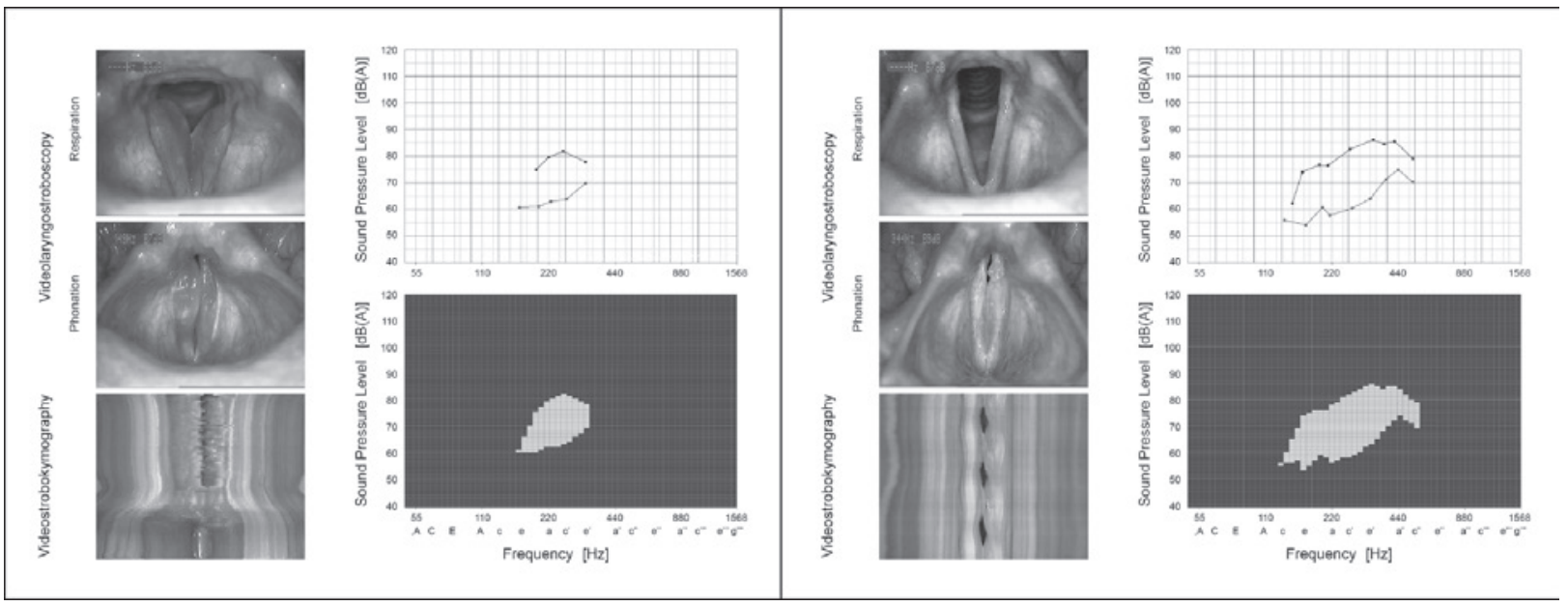

Fig. 2. Phonomicrosurgery-induced changes of objective findings in videolaryngostroboscopy [VLS], videostrobokymography, and VRP measurements in a 52-year-old female office worker with chronic manifestation of Reinke's edema (RE). Left: the preoperative status reveals bilateral RE (Yonekawa type III) with irregular vocal fold oscillations and absent mucosal wave propagation. The VRP envelope curves of loudest (black line) and softest singing (blue line) show small dynamic and frequency range. Polygon visualisation (green squares) depicts small VRP area, and VEM calculation results in a low value (VEM = 60). Right: three months postoperatively, the vocal folds present slim and irritation-free with a straight margin. The RE on both sides are completely removed, the healing process is finished (scar-free). The glottal closure is complete, vocal fold oscillations have normalised (mucosal wave propagation regular and symmetric). The VRP shows improved dynamic and frequency range with larger VRP area, hence VEM calculation results in a higher value (VEM = 100).

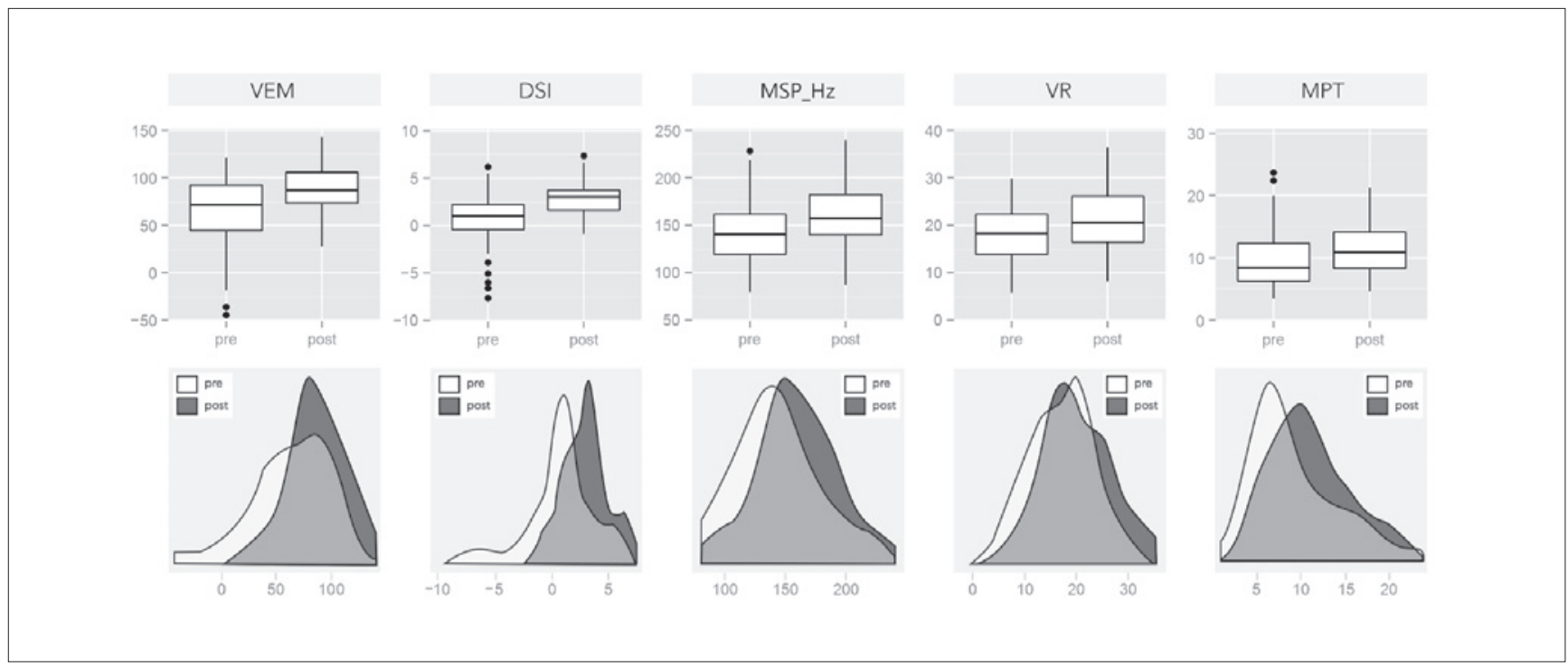

Fig. 3. Selected objective acoustic and aerodynamic parameters before and after RE removal (VEM, DSI, MSP_Hz, VR [semitones], and MPT [sec]) for all RE patients. Upper row: pre-/post-operative comparison via boxplots, which display the median, quartiles, range of values covered by the data, and any outliers (single spots). Lower row: pre-/post-operative comparison via kernel density curves (Gaussian smoothing), in which histograms were shifted and overlaid with smooth density estimates to illustrate the different distributions.

measures were calculated for the total RE group as well as separately for all oedema subtypes.

Concerning the auditory-perceptual evaluation using the RBH-system, blinded pre- vs post-operative com- parison showed that voices were less rough $(2.0 \pm 0.8$ vs $1.3 \pm 0.7)$, breathy $(1.2 \pm 0.6$ vs $0.7 \pm 0.6)$ and hoarse $(2.0 \pm 0.7$ vs $1.3 \pm 0.7)$. The interrater reliability exposed fair agreement between the six raters $(x=0.35)$. The VHI- 
Table II. Changes in vocal measures after RE removal for all patients and oedema subgroups. Data expressed as mean differences of pre- and postoperative values (upper line), with 95\% confidence intervals (lower line, in parentheses).

\begin{tabular}{|c|c|c|c|c|c|}
\hline Vocal measure & $\begin{array}{l}\text { RE total group } \\
\qquad(\mathrm{n}=60)\end{array}$ & $\begin{array}{l}\text { Marginal oedema group } \\
\qquad(n=4)\end{array}$ & $\begin{array}{l}\text { Type I Yonekawa group } \\
\qquad(\mathrm{n}=19)\end{array}$ & $\begin{array}{l}\text { Type II Yonekawa group } \\
\qquad(\mathrm{n}=29)\end{array}$ & $\begin{array}{l}\text { Type III Yonekawa group } \\
\qquad(\mathrm{n}=8)\end{array}$ \\
\hline VEM & $\begin{array}{c}24.57 \\
(16.89 ; 32.24)\end{array}$ & $\begin{array}{c}9.41 \\
(-0.57 ; 19.38)\end{array}$ & $\begin{array}{c}26.24 \\
(12.59 ; 39.90)\end{array}$ & $\begin{array}{c}20.77 \\
(9.43 ; 32.10)\end{array}$ & $\begin{array}{c}41.93 \\
(12.23 ; 71.63)\end{array}$ \\
\hline DSI & $\begin{array}{c}2.41 \\
(1.62 ; 3.20)\end{array}$ & $\begin{array}{c}0.32 \\
(-1.06 ; 1.69)\end{array}$ & $\begin{array}{c}1.87 \\
(1.05 ; 2.69)\end{array}$ & $\begin{array}{c}3.00 \\
(1.53 ; 4.46)\end{array}$ & $\begin{array}{c}2.61 \\
(0.37 ; 4.84)\end{array}$ \\
\hline MPT & $\begin{array}{c}1.68 \\
(0.48 ; 2.87)\end{array}$ & $\begin{array}{c}2.10 \\
(-1.48 ; 5.68)\end{array}$ & $\begin{array}{c}1.67 \\
(0.51 ; 2.84)\end{array}$ & $\begin{array}{c}2.20 \\
(0.27 ; 4.13)\end{array}$ & $\begin{array}{c}-0.45 \\
(-6.58 ; 5.68)\end{array}$ \\
\hline VR & $\begin{array}{c}3.55 \\
(1.79 ; 5.31)\end{array}$ & $\begin{array}{c}1.23 \\
(-5.22 ; 7.67)\end{array}$ & $\begin{array}{c}6.54 \\
(1.75 ; 11.33)\end{array}$ & $\begin{array}{c}1.86 \\
(0.32 ; 3.41)\end{array}$ & $\begin{array}{c}3.76 \\
(-0.42 ; 7.94)\end{array}$ \\
\hline I_min & $\begin{array}{c}-2.50 \\
(-4.08 ;-0.92)\end{array}$ & $\begin{array}{c}-0.25 \\
(-2.64 ; 2.14)\end{array}$ & $\begin{array}{c}-3.74 \\
(-6.83 ;-0.64)\end{array}$ & $\begin{array}{c}-1.76 \\
(-4.15 ; 0.63)\end{array}$ & $\begin{array}{c}-3.38 \\
(-8.74 ; 1.99)\end{array}$ \\
\hline F0_max & $\begin{array}{c}112.55 \\
(84.15 ; 140.95)\end{array}$ & $\begin{array}{c}31.75 \\
(-116.55 ; 180.05)\end{array}$ & $\begin{array}{c}118.26 \\
(56.89 ; 179.64)\end{array}$ & $\begin{array}{c}110.17 \\
(72.59 ; 147.76)\end{array}$ & $\begin{array}{c}148.00 \\
(55.99 ; 240.01)\end{array}$ \\
\hline F0_min & $\begin{array}{c}16.72 \\
(8.99 ; 24.44)\end{array}$ & $\begin{array}{c}-5.75 \\
(-27.85 ; 16.35)\end{array}$ & $\begin{array}{c}-0.74 \\
(-12.42 ; 10.94)\end{array}$ & $\begin{array}{c}24.83 \\
(16.29 ; 33.36)\end{array}$ & $\begin{array}{c}40.00 \\
(3.27 ; 76.73)\end{array}$ \\
\hline ST_max & $\begin{array}{c}6.28 \\
(4.37 ; 8.19)\end{array}$ & $\begin{array}{c}0.50 \\
(-4.78 ; 5.78)\end{array}$ & $\begin{array}{c}6.26 \\
(1.64 ; 10.89)\end{array}$ & $\begin{array}{c}6.03 \\
(3.95 ; 8.12)\end{array}$ & $\begin{array}{c}10.12 \\
(3.51 ; 16.74)\end{array}$ \\
\hline ST_min & $\begin{array}{c}2.70 \\
(1.53 ; 3.87)\end{array}$ & $\begin{array}{c}-1.00 \\
(-3.25 ; 1.25)\end{array}$ & $\begin{array}{c}-0.21 \\
(-1.88 ; 1.46)\end{array}$ & $\begin{array}{c}4.14 \\
(2.71 ; 5.56)\end{array}$ & $\begin{array}{c}6.25 \\
(1.48 ; 11.02)\end{array}$ \\
\hline ST_MSP & $\begin{array}{c}1.92 \\
(0.95 ; 2.88)\end{array}$ & $\begin{array}{c}-0.75 \\
(-3.14 ; 1.64)\end{array}$ & $\begin{array}{c}-0.47 \\
(-1.48 ; 0.53)\end{array}$ & $\begin{array}{c}3.24 \\
(2.03 ; 4.45)\end{array}$ & $\begin{array}{c}4.12 \\
(-0.59 ; 8.84)\end{array}$ \\
\hline MSP_Hz & $\begin{array}{c}16.82 \\
(9.26 ; 24.37)\end{array}$ & $\begin{array}{c}-7.00 \\
(-30.57 ; 16.57)\end{array}$ & $\begin{array}{c}-1.89 \\
(-11.36 ; 7.57)\end{array}$ & $\begin{array}{c}28.14 \\
(18.69 ; 37.59)\end{array}$ & $\begin{array}{c}32.12 \\
(-1.05 ; 65.30)\end{array}$ \\
\hline MSP_dB(A) & $\begin{array}{c}0.55 \\
(-0.65 ; 1.75)\end{array}$ & $\begin{array}{c}-0.75 \\
(-6.32 ; 4.82)\end{array}$ & $\begin{array}{c}-0.05 \\
(-2.41 ; 2.31)\end{array}$ & $\begin{array}{c}0.62 \\
(-1.23 ; 2.47)\end{array}$ & $\begin{array}{c}2.38 \\
(-0.94 ; 5.69)\end{array}$ \\
\hline Jitter & $\begin{array}{c}-0.83 \\
(-1.37 ;-0.29)\end{array}$ & $\begin{array}{c}0.00 \\
(-0.02 ; 0.03)\end{array}$ & $\begin{array}{c}-0.09 \\
(-0.18 ; 0.00)\end{array}$ & $\begin{array}{c}-1.42 \\
(-2.45 ;-0.38)\end{array}$ & $\begin{array}{c}-0.86 \\
(-2.44 ; 0.73)\end{array}$ \\
\hline VHI & $\begin{array}{c}-6.43 \\
(-8.57 ;-4.30)\end{array}$ & $\begin{array}{c}-10.75 \\
(-19.79 ;-1.71)\end{array}$ & $\begin{array}{c}-4.79 \\
(-9.04 ;-0.54)\end{array}$ & $\begin{array}{c}-7.14 \\
(-10.46 ;-3.81)\end{array}$ & $\begin{array}{c}-5.62 \\
(-10.56 ;-0.69)\end{array}$ \\
\hline VHIs & $\begin{array}{c}-0.72 \\
(-0.98 ;-0.45)\end{array}$ & $\begin{array}{c}-0.75 \\
(-1.55 ; 0.05)\end{array}$ & $\begin{array}{c}-0.68 \\
(-1.19 ;-0.17)\end{array}$ & $\begin{array}{c}-0.69 \\
(-1.10 ;-0.28)\end{array}$ & $\begin{array}{c}-0.88 \\
(-1.82 ; 0.07)\end{array}$ \\
\hline
\end{tabular}

VEM: vocal extent measure; DSI: dysphonia severity index; MPT: maximum phonation time; VR: vocal range; I_min: lowest vocalization; FO_max: highest tone; FO_min: lowest tone; ST: semitones related to the hearing threshold of $16 \mathrm{~Hz}$ (ST_max, ST_min, ST_MSP); MSP: mean speaking pitch [MSP_dB(A), MSP_Hz); VHI: voice handicap index; VHIs: self-perceived impairment of voice at the present time.

9i questionnaire showed a decrease from an average of $18 \pm 8$ to $12 \pm 9$ points. The VHIs demonstrated an improvement of the self-perceived impairment of the voice from moderately $(2 \pm 1)$ to mildly disturbed $(1 \pm 1)$. All these improvements were found significant at the $0.1 \%$ level. The pre- and post-therapeutic subjective vocal parameters are graphically displayed in Figure 4.

\section{Discussion}

Our pre-operative data confirms that RE most often develops in smoking and middle-aged women ( $>40$ years), with association to the risk factors vocal overuse and laryngopharyngeal reflux ${ }^{13}$ 7-10 13-15. The initial distribution of oedema subtypes according to severity (Yonekawa classification) was conspicuous: type III occurred exclusively and type II more often in non-professional voice users, whereas in professionals (singers and speakers) a mild form of marginal oedema was seen more frequently. It seems that people who are reliant on their voice in their job are more sensitive to vocal changes, feel affected faster and therefore go earlier to see a voice doctor.

This study aimed at examining the outcome of phonomicrosurgery in RE by evaluating the changes in subjective and objective vocal parameters. Our results revealed a considerable improvement of vocal function. This corresponds to other studies concluding that microlaryngoscopic RE ablation has a beneficial effect on perceptual and acoustic voice parameters. However, most RE studies 

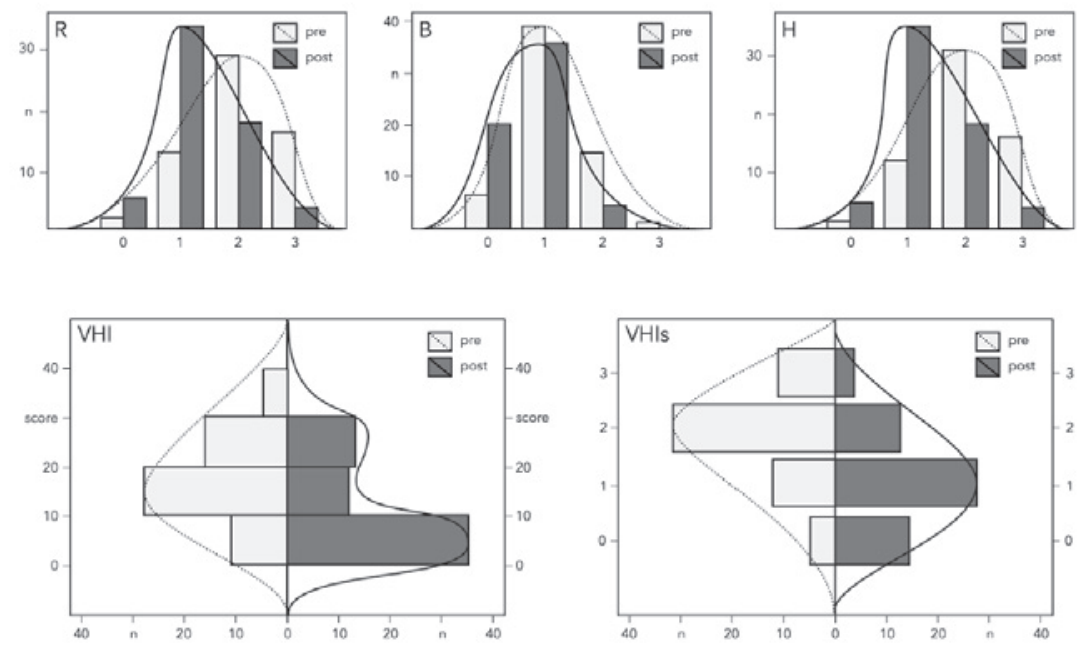

Fig. 4. Subjective vocal parameters before and after RE removal. Upper row: comparison of pre- and post-operative voice parameters according to the RBHsystem. Lower row: comparison of pre- and post-operative VHI-9i and VHIs scores.

analysed the change in speaking fundamental frequency and subjective vocal parameters ${ }^{28-3032}$.

Lim et al. (2006) ${ }^{29}$ studied $61 \mathrm{RE}$ patients and 30 controls. They detected that the mean fundamental frequency was lowered: the more severe the oedema, the greater the difference with the control group. Re-evaluation of 23 patients two months after surgery showed, that the mean fundamental frequency was increased to almost normal values and vocal efficiency had improved. Šiupšinskienė and Skumanienè (2002) ${ }^{30}$ compared different surgical techniques in the treatment of 62 RE patients. They showed that surgical preservation of VF medial edges mucosa yields best benefit for voice quality. As in our subjective results, reductions in grade of $\mathrm{H}$ and $\mathrm{R}$ were found and the voices were judged as improved in most cases. Still, the mean values of many voice parameters in early postsurgical period significantly differed from normal, but the evaluation took place on average after 24 days, which is quite short according to our experience. Tan et al. (2010) ${ }^{31}$ presented an "M" shaped microflap for the treatment of bi-lobular and also centrally located RE using $\mathrm{CO}_{2}$ laser and/or cold micro-instruments, allowing maintenance of an appropriate amount of SLP and easy coverage of the potentially exposed part of the ligament. This procedure was carried out in 11 patients with very good results in terms of fast recovery and improvement of voice quality; however, specific vocal parameters were not described in detail. Sant'Anna and Mauri (2000) ${ }^{32}$ showed in a small population of 5 patients that resection of RE using the microdebrider also led to a satisfying vo- cal outcome. There was recovery in loudness and pitch, and voices changed from rough and breathy to normal or near-normal. This results from taking great care with the mucosa, SLP and vocal ligament to avoid iatrogenic scarring.

In our study, all subjective and objective parameters except for MSP_dB(A) improved significantly. MSP_dB(A) slightly increased post-operatively, suggesting that patients were able to speak louder. As many factors influence loudness of mean speaking voice, this parameter does not reliably reflect vocal capability. Most patients felt their voice to be more clear and stable, which was visually confirmed by VLS which showed regular and symmetric VF oscillations. Furthermore, MSP_Hz increased, and R and $\mathrm{H}$ decreased, so that the main characteristics of RE, a deep and hoarse voice, changed to the direction of a normal voice. The limited reliability of agreement between all six raters when assigning categorical $\mathrm{RBH}$ ratings to the blinded patient's voices seems to result from the reduced experience and training level in three of the participants (2 medical students, 1 medical technical assistant). According to the self-perception recorded with the VHI-9i-questionnaire, patients reported their voice to be significantly better after surgery. However, our study is lacking a control group to compare if patients in fact reached normal levels of MSP_Hz or if they remained below.

As a novelty, we collected a number of vocal parameters which can give further information about the magnitude of vocal improvement induced by phonomicrosurgery. Among the acoustic measurements, we especially inves- 
tigated the VEM, which is not yet commonly established in phoniatric diagnostics, but has been demonstrated to be a suitable parameter for objective quantification of vocal performance in patients with VF polyps ${ }^{21}$. Even in RE patients, VEM and DSI correlated positively with each other and negatively with age as well as $\mathrm{R}$ and $\mathrm{H}$. There was no correlation with $\mathrm{B}$. This is understandable as $\mathrm{R}$ and $\mathrm{H}$ strongly correlated with each other indicating that roughness determines the impression of overall hoarseness in RE. The measurements VEM and DSI can be seen as comparable parameters that are related to each other. Dysphonia reduces the vocal capacity that can be measured by both parameters. However, whereas the DSI reflects the severity of dysphonia as a negative criterion, the newly developed VEM describes the vocal abilities and enables a classification of voice performance as a positive criterion. However, our investigations also confirmed differences between both parameters. Some patients had comparable DSI values, but revealed different VRPs with different values for the VEM. This example shows the significant influence of the recorded acoustic and aerodynamic parameters in the multidimensional DSI calculation. Previous studies also indicated that the DSI is influenced by differences of measurements in the registration programs as well as by age or gender ${ }^{33}{ }^{34}$. Therefore, we saw the need to develop and investigate the VEM as an objective parameter unimpaired by these interacting factors. The VEM calculation avoids the inclusion of elements that are highly susceptible to interference (e.g. jitter). The VEM is also independent of pitch (i.e. women's and men's voices are evaluated in the same way) and vocal intensity (i.e. microphone distance has no influence on the assessment of the VRP). It represents a comprehensible and user-friendly objective measure of voice function and quantifies the VRP one-dimensionally by a single concrete value, instead of estimating it by visual perception and a few exposed values. The VEM is calculated automatically from the VRP and may be easily implemented into existing clinical protocols and evaluated. The resulting new parameter of vocal capacity provides additional information about voice function. Therefore, the introduction of the VEM in practical objective voice diagnostics is appropriate and desirable, complementing the established DSI.

Moreover, we examined the quantitative changes in vocal parameters caused by microlaryngoscopic excision of RE. The degree of improvement and the concrete extent of benefits are revealed by the mean differences between pre- and post-therapeutic voice parameters and $95 \%$ confidence intervals. The range of improvement of VEM (17 to 32 ), DSI (1.6 to 3.2$)$, MPT (0.5 to 2.9 seconds), VR
(2 to 5 semitones), MSP (1.0 to 2.9 semitones) and VHI ( -9 to -4$)$ could serve for quality control after phonomicrosurgical removal of RE as well as reference range for subjective and objective expectation values.

\section{Conclusions}

The use of VEM in RE patients objectifies and quantifies vocal capacity as documented in the VRP. Phonomicrosurgery is an effective and safe, subjectively and objectively satisfactory therapy to improve vocal function in patients suffering from RE. Essential requirements comprise a competent and precise microlaryngoscopic excision leaving some gelatinous material in the SLP, a normal post-operative course with regular wound healing, vocal rehabilitation and avoiding smoking to reduce the risk of RE recurrence.

\section{References}

1 Artico M, Bronzetti E, Ionta B, et al. Reinke's Edema: investigations on the role of MIB-1 and hepatocyte growth factor. Eur J Histochem 2010;54:e30.

2 Pickhard A, Reiter R. Benign vocal fold lesions. Laryngorhinootologie 2013;92:304-12.

3 Zeitels SM, Hillman RE, Bunting GW, et al. Reinke's edema: phonatory mechanisms and management strategies. Ann Otol Rhinol Laryngol 1997;106(7 Pt 1):533-43.

4 Bohlender J. Diagnostic and therapeutic pitfalls in benign vocal fold diseases. GMS Curr Top Otorhinolaryngol Head Neck Surg 2013;12:Doc01.

5 Dikkers FG, Nikkels PG. Lamina propria of the mucosa of benign lesions of the vocal folds. Laryngoscope 1999;109:1684-9.

6 Hantzakos A, Remacle M, Dikkers FG, et al. Exudative lesions of Reinke's space: a terminology proposal. Eur Arch Otorhinolaryngol 2009;266:869-78.

7 Cipriani NA, Martin DE, Corey JP, et al. The clinicopathologic spectrum of benign mass lesions of the vocal fold due to vocal abuse. Int J Surg Pathol 2011;19:583-7.

8 Goswami S, Patra TK. A Clinico-pathological study of Reinke's oedema. Indian J Otolaryngol Head Neck Surg 2003;55:160-5.

9 Branski RC, Saltman B, Sulica L, et al. Cigarette smoke and reactive oxygen species metabolism: implications for the pathophysiology of Reinke's edema. Laryngoscope 2009;119:2014-8.

10 Lim S, Sau P, Cooper L, et al. The incidence of premalignant and malignant disease in Reinke's edema. Otolaryngol Head Neck Surg 2014;150:434-6.

11 Martins RH, Fabro AT, Domingues MA, et al. Is Reinke's edema a precancerous lesion? Histological and electron microscopic aspects. J Voice 2009;23:721-5. 
12 Rosen CA, Simpson CB. Operative techniques in Laryngology. Berlin, Germany: Springer; 2008.

13 Marcotullio D, Magliulo G, Pezone T. Reinke's edema and risk factors: clinical and histopathologic aspects. Am J Otolaryngol 2002;23:81-4.

14 Hah JH, Sim S, An SY, et al. Evaluation of the prevalence of and factors associated with laryngeal diseases among the general population. Laryngoscope 2015;125:2536-42.

15 Chung JH, Tae K, Lee YS, et al. The significance of laryngopharyngeal reflux in benign vocal mucosal lesions. Otolaryngol Head Neck Surg 2009;141:369-73.

16 Kravos A, Zupevc A, Cizmarevic B, et al. The role of allergy in the etiology of Reinke's edema on vocal folds. Wien Klin Wochenschr 2010;122(Suppl 2):44-8.

17 Lumpkin SM, Bennett S, Bishop SG. Postsurgical follow-up study of patients with severe polypoid degeneration. Laryngoscope 1990;100:399-402.

18 Zhukhovitskaya A, Battaglia D, Khosla SM, et al. Gender and age in benign vocal fold lesions. Laryngoscope 2015;125:191-6.

19 Dursun G, Ozqursoy OB, Kemal O, et al. One-year follow-up results of combined use of $\mathrm{CO}_{2}$ laser and cold instrumentation for Reinke's edema surgery in professional voice users. Eur Arch Otorhinolaryngol 2007;264:1027-32.

20 Højslet PE, Moesgaard-Nielsen V, Karlsmose M. Smoking cessation in chronic Reinke's oedema. J Laryngol Otol 1990;104:626-8.

21 Salmen T, Ermakova T, Möller A, et al. The value of Vocal Extent Measure (VEM) assessing phonomicrosurgical outcomes in vocal fold polyps. J Voice 2017;31:114.e7-e15.

22 Caffier PP, Schmidt B, Gross M, et al. A comparison of white light laryngostroboscopy versus autofluorescence endoscopy in the evaluation of vocal fold pathology. Laryngoscope 2013;123:1729-34.

23 Yonekawa H. A clinical study of Reinke's edema. Auris Nasus Larynx 1988;15:57-78.
24 Nawka T, Sittel C, Arens C, et al. Voice and respiratory outcomes after permanent transoral surgery of bilateral vocal fold paralysis. Laryngoscope 2015;125:2749-55.

25 Wuyts F, De Bodt M, Molenberghs G, et al. The Dysphonia Severity Index: an objective measure of vocal quality based on a multiparameter approach. J Speech Lang Hear Res 2000;43:796-809.

26 Ptok M, Schwemmle C, Iven C, et al. On the auditory evaluation of voice quality. HNO 2006;54:793-802.

27 Nawka T, Verdonck-de Leeuw IM, De Bodt M, et al. Item reduction of the voice handicap index based on the original version and on European translations. Folia Phoniatr Logop 2009;61:37-48.

28 Stuut M, Tjon Pian Gi RE, Dikkers FG. Change of Voice Handicap Index after treatment of benign laryngeal disorders. Eur Arch Otorhinolaryngol 2014;271:1157-62.

29 Lim JY, Choi JN, Kim KM, et al. Voice analysis of patients with diverse types of Reinke's edema and clinical use of electroglottographic measurements. Acta Otolaryngol 2006;126:62-9.

30 Siupsinskiene N, Skumaniene M. Phonatory characteristics following different endolaryngeal microsurgical techniques in Reinke's disease. Medicina (Kaunas) 2002;38:982-9.

31 Tan NC, Pittore B, Puxeddu R. The " $M$ " shaped microflap for treatment of complex Reinke's Space Oedema of the vocal cords. Acta Otorhinolaryngol Ital 2010;30:259-63.

32 Sant'Anna GD, Mauri M. Use of the microdebrider for Reinke's edema surgery. Laryngoscope 2000;110:2114-6.

33 Aichinger $\mathrm{P}$, Feichter $\mathrm{F}$, Aichstill $\mathrm{B}$, et al. Inter-device reliability of DSI measurement. Logoped Phoniatr Vocol 2012;37:167-73.

34 Hakkesteegt MM, Brocaar MP, Wieringa MH, et al. Influence of age and gender on the dysphonia severity index. A study of normative values. Folia Phoniatr Logop 2006;58:264-73.

Received: December 13, 2016 - Accepted: July 26, 2017

Address for correspondence: Philipp P. Caffier, Department of Audiology and Phoniatrics of Charité, University Medicine Berlin, Chariteplatz 1, D-10117 Berlin, Germany. Tel. +49 30450555402. Fax +49 30450555 931. E-mail: philipp.caffier@charite.de 